\title{
Especial Globo 50 anos: da rememoração à historicidade mediada
}

\author{
"Especial Globo 50 anos": from the remembrance of mediated historicity \\ “Especial Globo 50 anos": de la rememoración a la historicidad mediada
}

DOI: https://doi.org/10.1590/1809-5844202113

Juliana Vieira Borges ${ }^{1}$

http://orcid.org/0000-0001-7555-3716

Humberto Junio Alves Viana ${ }^{2}$

http://orcid.org/0000-0001-7468-6402

Christina Ferraz Musse ${ }^{2}$

http://orcid.org/0000-0002-3107-3734

Daniel Carvalho de Rezende ${ }^{3}$

http://orcid.org/0000-0003-1277-724X

${ }_{1}^{1}$ (Universidade Federal dos Vales do Jequitinhonha e Mucuri, Departamento de Administração. Teófilo Otoni - MG, Brasil. Universidade Federal de Lavras, Programa de Pós-Graduação em Administração. Lavras - MG, Brasil).

${ }^{2}$ (Universidade Federal de Juiz de Fora, Faculdade de Comunicação, Programa de Pós-Graduação em Comunicação. Juiz de Fora - MG, Brasil).

${ }_{3}^{3}$ (Universidade Federal de Lavras, Departamentos de Administração e Economia, Programa de Pós-Graduação em Administração. Lavras - MG, Brasil).

\section{Resumo}

Em 2015, na ocasião de seu cinquentenário, a Rede Globo desenvolveu programas que visavam a rememorar sua trajetória institucional. Um desses programas foi intitulado de "Especial Globo 50 anos” e fez um retrospecto dos principais setores da emissora. O artigo que se segue propõe, dessa forma, analisar o programa a fim de perceber como a narrativa memorialística reafirmou o lugar de importância da emissora e ressaltou um legado perante seus receptores. Com o propósito de atender a esses objetivos utilizou-se metodologicamente da "análise da materialidade audiovisual” e do termo "historicidade mediada" proposto por Thompson. Os resultados alcançados demonstraram 
que o aniversário da instituição foi fundamental para o constructo de um processo de rememoração que se materializou por meio de uma gama de programas. Estes, em especial o programa analisado, definiram um lugar na História, enquanto mérito, ocupado e ressignificado pela emissora.

Palavras-chave: Audiovisual. Memória. Rememoração. Historicidade Mediada. Rede Globo.

\begin{abstract}
In 2015, on the occasion of its fiftieth anniversary, "Rede Globo" developed programs that aimed to recall its institutional trajectory. One such program was entitled "Globo Special 50 years" and made a retrospective of the main sectors of the station. The following article proposes, therefore, to analyze the program in order to understand how the memorial narrative reaffirmed the place of importance of the station and highlighted a legacy before its recipients. In order to meet these objectives, a methodological analysis of the "audiovisual materiality analysis" and the term "mediated historicity" proposed by Thompson was used. The results showed that the anniversary of the institution was fundamental for the construction of a process of recollection that materialized through a range of programs. These, in particular the analyzed program, defined a place in History, as merit, occupied and resignified by the transmitter.
\end{abstract}

Keywords: Audiovisual. Memory. Recollection. Mediated historicity. Rede Globo.

\title{
Resumen
}

En 2015, en la ocasión de su cincuentenario, la Red Globo desarrolló programas que pretendían rememorar su trayectoria institucional. Uno de esos programas fue titulado de "Especial Globo 50 años” e hizo una retrospectiva de los principales sectores de la emisora. El siguiente artículo propone analizar el programa para percibir cómo la narrativa conmemorativa reafirmó el lugar de importancia de la emisora y subrayó un legado ante sus receptores. Con el propósito de atender a esos objetivos se utilizó metodológicamente del “análisis de la materialidad audiovisual” y del término "historicidad mediada” propuesto por Thompson. Los resultados alcanzados demostraron que el aniversario de la institución fue fundamental para el constructo de un proceso de rememoración que se materializó a través de una gama de programas. Estos, en especial el programa analizado, definieron un lugar en la Historia, en cuanto mérito, ocupado y resignificado por la emisora.

Palabras-clave: Audiovisual. Memoria. Recogimiento. Mediated historicidade. Rede Globo.

\section{Introdução}

No dia 26 de abril de 2015, a maior empresa de comunicação televisiva do Brasil, a Rede Globo, completou cinquenta anos desde a sua fundação. O contexto de seu cinquentenário permitiu à emissora produzir uma gama de programas a fim de exaltar sua importância perante a sociedade brasileira. Um desses programas, “Especial Globo 50 Anos”, fez um retrospecto da trajetória da emissora por meio de um show com a narração dos jornalistas Pedro Bial e Fátima Bernardes. Este foi exibido numa noite de sábado, no dia 25 de abril 
de 2015, e contou com a participação de todos os setores da emissora, principalmente de personalidades consideradas marcantes em sua trajetória.

O texto que se segue busca analisar a narrativa do programa à luz do aporte teórico de Thompson (2009), Nora (1995) e Barbosa (2006, 2016). Esses autores estudam as mediações que os meios de comunicação fazem do passado à luz de contextos outros de produção. Dessa forma, estabelece-se o que Thompson (2009) denominou de historicidade mediada, mais precisamente, as formas que os indivíduos se relacionam com o passado por meio dos veículos de comunicação.

No que tange à metodologia, utiliza-se da Análise da Materialidade Audiovisual proposta por Coutinho (2016). Assim, considerando esta metodologia e a base teórica citada, analisa-se o programa a fim de compreender como a rememoração serve de espaço privilegiado para que a emissora dite aquilo que deve ser lembrado ou esquecido relativo à sua trajetória institucional. E, em última instância, definir um lugar na história e mediar, em consequência disso, sua importância perante o público cada vez mais fragmentado da contemporaneidade.

\section{“Especial Globo 50 anos”: a efeméride e a construção de um lugar simbólico}

O programa “Especial Globo 50 anos” apresentou, entre suas principais características, o objetivo de retratar as cinco décadas da instituição Rede Globo. Dividiu-se, portanto, em quadros, nos quais mostrou os principais produtos da teledramaturgia, do telejornalismo e do entretenimento. De forma clara, o programa buscou trabalhar conceitos de autenticidade, de superação e de adaptabilidade da emissora durante seus anos de existência.

O contexto de produção do programa, o ano de 2015, reflete a necessidade de rememoração das sociedades contemporâneas ocidentais (HUYSSEN, 2000). Essa necessidade data do final do século XX e está inserida em diversos setores, desde o "boom" das modas retrô, passando pela comercialização em massa da nostalgia, até a difusão de práticas memorialísticas nas artes visuais.

De acordo com Lipovetsky e Charles (2004), as lógicas desta sociedade caracterizamse pelo nascedouro do "tudo-patrimônio" e do "todo comemorativo". Celebram-se até o menor objeto do passado e remobilizam-se as tradições que são estruturadas sobre bases contraditórias. Isso pressupõe um presente que não para de desenterrar o passado. "Dizem de brincadeira que abre um museu por dia na Europa e já se perdeu a conta das comemorações de aniversário dos grandes e nem tão grandes acontecimentos históricos” (LIPOVETSKY; CHARLES, 2004, p. 14). Ainda, segundo eles, o que se vê é o reinado do infinito, de um presentismo excessivo em conformidade com o deslocamento da memória à hipermemória, esta última caracterizada como uma vontade de rememoração calcada na busca desenfreada por raízes e por ancoragem nos tempos idos.

Neste contexto, as obras do passado já não são contempladas em recolhimento e silêncio, mas, sim, devoradas em segundos, funcionando como objeto de animação de 
massa, espetáculo atraente, uma maneira de diversificar o lazer e matar o tempo de instantaneamente. Acima de tudo, na sociedade contemporânea, o antigo e o nostálgico se tornaram argumentos comerciais e ferramentas mercadológicas. “[...] Fazem parte de um processo de construção de poder, no qual o interesse político de dominar o tempo assume papel primordial” (BARBOSA, 2006, p. 18).

Em conformidade com Huyssen (2000), não é mais possível pensar em qualquer trauma histórico como uma questão ética e política séria, sem levar em conta os múltiplos modos com que ele está agora ligado à mercadorização e à espetacularização em filmes, museus, docudramas, sites da internet, livros de fotografia, histórias em quadrinhos, ficção, e até contos de fadas e música popular. Esta disseminação da memória é ampla, tanto geográfica quanto politicamente, podendo, inclusive, ser usada, por exemplo, como mecanismo de legitimação, na "americanização do holocausto” (HUYSSEN, 2000) ou no discurso narrativo do programa que se propõe analisar.

Com vistas a compreender melhor o conceito de memória, é necessário amparar-se nas discussões estabelecidas principalmente por dois autores: Halbwachs (2006) e Nora (1993). De acordo com Halbwachs (2006, p. 33), “[...] para evocar seu próprio passado, em geral, a pessoa precisa recorrer às lembranças de outras, e se transporta a pontos de referência que existem fora de si, determinados pela sociedade”. A memória passa a ser, então, encarada por ele como um fato social que pode ser demarcado por padrões comportamentais. Isso quer dizer que a memória individual está atrelada aos diversos grupos sociais que circundam uma pessoa, bem como é a combinação eventual dos diferentes meios dos quais o indivíduo sofre influência.

Contudo, existem motivos para distinguir duas memórias - uma interior e a outra exterior, i.e., uma memória pessoal e a outra social.

[...] A primeira [memória interior] receberia ajuda da segunda [memória exterior], já que afinal de contas a história de nossa vida faz parte da história em geral. A segunda, naturalmente, seria bem mais extensa do que a primeira. Por outro lado, ela só representaria para nós o passado sob uma forma resumida e esquemática, ao passo que a memória de nossa vida nos apresentaria um panorama bem mais contínuo e mais denso (HALBWACHS, 2006, p. 34).

Enquanto Halbwachs (2006) enfatiza a incorporação das memórias pela história conforme essas vão deixando gradualmente de existir a partir do desaparecimento dos grupos que as sustentavam, Nora (1993) defende o que chama de “metamorfose contemporânea”, que significa a inexistência da memória e a sobreposição dessa pela história de maneira ampla.

Segundo Nora (1993, p. 7), “[...] fala-se tanto de memória porque ela não existe mais”. Isso quer dizer que o que se vê na contemporaneidade é o estabelecimento de lugares de memória com o propósito de encarná-las e resguardá-las de um possível esquecimento. Uma sociedade em que o medo da fragmentação memorialística leva ao domínio do patrimônio. 
Por isso, “[...] se habitássemos ainda nossa memória, não teríamos necessidade de lhe consagrar lugares” (NORA, 1993, p. 7).

É possível perceber, nesse sentido, que a produção do programa “Especial Globo 50 anos” vislumbrou narrar a trajetória da emissora como uma forma de resguardar memórias ameaçadas pelo decorrer do tempo. Buscou-se, assim, balizar a memória, a fim de resguardar e reafirmar a atuação da Rede Globo ao longo de seus cinquenta anos.

Outro ponto importante é perceber que os discursos cronologicamente situados no passado constroem o presente, uma vez que "[...] a linguagem que articula e sustenta a memória, já por si só inoculadora de valores institucionais, é modelada para reelaborar o passado através do presente” (MOTTER, 2001, p. 2). Dessa forma, o programa de rememoração estimula uma memória nacional, que não é espontânea. Todos os traços, os esquecimentos e os silêncios revelam mecanismos de manipulação da memória coletiva.

E Le Goff (1996, p. 141) resume muito bem tais pretensões. Segundo ele, “[...] tornarse senhores de memória e do esquecimento é uma das grandes preocupações das classes, dos grupos, dos indivíduos que dominaram ou dominam as sociedades históricas”. Por isso, a partir do momento em que a Rede Globo desenvolveu um programa para mostrar sua trajetória institucional, os telespectadores que o assistiram tiveram contato com um passado recriado à luz de um contexto de produção, em toda a complexidade que isso possa representar.

Inseridas no contexto anteriormente citado, as empresas contemporâneas têm entre suas principais preocupações a preservação memorialística de sua trajetória institucional. Os centros de memória institucional são um espaço relativamente recente, datados dos anos 2000, e utilizados principalmente como estratégia de gestão, como potencializadores de um lugar de fala pautado por experiência e tradição.

Segundo Pazin (2015), um centro de memória é um setor ou unidade de cada instituição que busca reunir, organizar, conservar e produzir conteúdo a partir da memória institucional, utilizando-se tanto de documentação histórica da organização quanto da memória de seus colaboradores e de outros atores caros à sua vida institucional. $\mathrm{O}$ aspecto documental é apenas uma parcela da totalidade das informações memorialísticas de uma instituição, pois elas também estão nas pessoas. Parte significativa do trabalho realizado nestes centros é justamente coletar a memória dessas pessoas utilizando diversas ferramentas e metodologias de registro, como a da história oral, com a realização de entrevistas. Este acervo é importante também pelo uso que se pode fazer dele. Isso porque a preservação da memória de uma instituição pode ser o repositório a partir do qual é possível desenvolver projetos, serviços e produtos.

Com este panorama, a Rede Globo, desde a década de 1990, desenvolve o "Projeto Memória Globo”, marcado por uma série de iniciativas das empresas de comunicação do grupo da família Marinho, buscando preservar a memória dos veículos que as compõem. Segundo a emissora, por meio de seu site, os integrantes do projeto fazem diversas entrevistas e pesquisas para a obtenção de informações. Dentre os frutos do trabalho do grupo, destacamse: (i) o "Dicionário da TV Globo", que traz em verbetes os programas produzidos pela 
emissora nos setores de teledramaturgia e entretenimento, lançado em 2003; (ii) o livro “Roberto Marinho", escrito pelo jornalista Pedro Bial, que traz um perfil biográfico do antigo dono da empresa e jornalista, falecido em 2003; (iii) o livro "Almanaque da TV Globo”, lançado no ano de 2006, com os principais programas desde a sua inauguração; (iv) o livro “Jornal Nacional: a notícia faz história”, lançado em 2004, nas comemorações dos 35 anos do noticiário; (v) o site oficial lançado no dia 7 de junho de 2008, em comemoração aos 43 anos da emissora; e (vi) o livro "Autores: histórias da teledramaturgia”, lançado no final de 2008, com 16 autores da emissora.

Além destes produtos, a emissora também produziu especiais em comemoração aos seus aniversários de fundação. E, em todos os anos, desde 1967, leva às telas o programa de retrospectiva que busca salientar a onipresença da emissora nos vários acontecimentos anuais. As publicações e os produtos audiovisuais citados demonstram que a preservação da memória do grupo Globo possibilitou ganhos mercadológicos importantes, e também a delimitação de um lugar simbólico na sociedade brasileira.

Segundo Pazin (2015), embora seja nova a ideia de que a memória de uma organização possa ser utilizada como estratégia para sua administração, ao longo dos anos, ela tem sido percebida como um fator importante para a reputação das organizações, ao demonstrar como os valores e a missão institucional podem ser responsáveis pelo fortalecimento de sua imagem junto ao público externo. Portando, rememorar a trajetória de uma instituição, para além de uma necessidade atual, tal como demostrou Huyssen (2000) e Nora (1995), é uma ferramenta de construção simbólica considerada eficiente e importante.

\section{A historicidade mediada}

Segundo Thompson (2009), no passado da história humana, em suas diversas conjunturas, as interações sociais eram somente face a face, ou seja, a partir da aproximação e de trocas dentro de ambientes físicos compartilhados. Estas interações, segundo ele, eram marcadas pelas tradições orais que se manifestavam de acordo com um processo contínuo de renovação e de reinvenção através de inúmeros atos criativos. Embora abertas em conteúdo, eram restritas em termos de alcance geográfico. Dependiam, portanto, da interação face a face e do deslocamento físico dos indivíduos.

Contudo, o desenvolvimento dos meios de comunicação, a partir do século XV, articulou novas formas de ação, interação e tipos de relacionamentos sociais. Os meios promoveram, a partir de então, uma complexa reorganização dos padrões de interação humana através do tempo e do espaço. A comunicação propiciou, dessa forma, a interação entre indivíduos que não compartilhavam o mesmo ambiente espaço-temporal, diferenciando-se radicalmente do modelo preexistente.

Foi com o surgimento da indústria da imprensa e, posteriormente, com a emergência dos diversos meios eletrônicos de comunicação, que a disseminação das formas de interação 
mediadas e quase mediadas modificou as características da vida social do mundo moderno (ou hipermoderno), agora repleto de interações que perderam seu caráter imediato.

A televisão aparece, dessa forma, como marca característica da quase interação mediada. Tecnicamente falando, uma de suas conquistas é a sua capacidade de utilizar uma grande quantidade de deixas simbólicas tanto auditivas quanto visuais. Ainda no caso da televisão, segundo Thompson (2009), os indivíduos que se comunicam através dela podem ser vistos agindo dentro de um específico contexto espaço-temporal.

Na quase interação proporcionada pela televisão, processa-se, de acordo com Thompson (2009), o trancamento de três agrupamentos de coordenadas (coordenadas espaçotemporais de produção, coordenadas espaço-temporais da mensagem televisiva, coordenadas espaço-temporais dos diversos contextos de recepção), o que se denomina de "interpolação espaço-temporal”. Nesse sentido, ao ter contato com as mensagens televisivas, os indivíduos receptores se orientam cotidianamente para outros espaços e tempos diversos daqueles que caracterizam seus contextos de recepção. $\mathrm{O}$ autor denominou este processo de experiência espaço-temporal descontínua.

Assim, os meios de comunicação de massa, especialmente a televisão, introduzem novos e importantes elementos na vida política e social ao tornar disponível aos indivíduos imagens e informações de acontecimentos e de lugares muito além de seus ambientes sociais imediatos. Este fenômeno demonstra que a mídia não se preocupa em apenas descrever o mundo social, mas se envolve ativamente na construção dele, modelando e influenciando o curso dos acontecimentos, e ainda criando acontecimentos que poderiam não ter acontecido em sua ausência.

Dessa forma, a mídia fornece ao sujeito novas experiências (experiências mediadas), novos sentidos de pertencimento (sociabilidade mediada) e sentidos de passado (historicidade mediada) (THOMPSON, 2009). Oferece, também, recursos simbólicos que atuam como possibilidades para a construção de um saber sobre si. Se antes da mídia uma das formas de obter sentidos para a formação das identidades era a interação face a face, com o avanço dos meios de comunicação e da imprensa, as informações passaram a chegar ao sujeito por meio das mediações.

O objeto deste artigo, o programa “Especial Globo 50 anos”, é característico das preocupações institucionais da contemporaneidade e fomenta a exaltação da emissora perante a sociedade que o assiste. O programa, como já citado anteriormente, faz uma cronologia, apresentando a atuação da emissora ao longo de seus 50 anos. A produção dele revela o que Nora (1995) discute em seu texto sobre a relação entre os meios de comunicação e a construção histórica. Segundo ele, os acontecimentos históricos são fruto da mediação feita pelos meios de comunicação, o que quer dizer que só se torna histórico aquilo que se faz conhecer por meio deles. “[...] Imprensa, rádio, imagens não agem como meios dos quais os acontecimentos seriam relativamente independentes, mas como a própria condição de sua existência” (NORA, 1995, p. 181). 
Os meios de comunicação de massa seriam, dessa forma, portadores da elevação de sentido dada à história, o que Thompson (2009) denominou de "historicidade mediada", ou seja, as formas pelas quais as pessoas se relacionam com o tempo passado e com a interpretação e transmissão dos fatos, principalmente por meio dos veículos de comunicação. Segundo Vicente,

[...] A massificação e o crescimento tecnológico colocam em risco as narrativas face a face e as interações sociais, fruto dessa relação. Dessa maneira, ocorre um acréscimo na hora de transmitir as experiências do passado, acréscimo esse que se dá em função da incorporação e da exposição das pessoas às mídias e aos seus conteúdos. Por esse motivo, Thompson acredita que as noções de tempo e espaço passam por transformações. O sentido de pertencimento das pessoas agora é mediado pela comunicação e pelos fatos por ela divulgados (2009, p. 51).

A princípio, numa observação superficial do objeto, é possível identificar que a Rede Globo buscou mostrar sua capacidade de adaptação, sua brasilidade e sua onipresença na casa dos brasileiros. Buscou mostrar, também, que tem a deixar um legado para a posteridade. Em suma, a emissora esforçou-se para destacar o quão histórica é para aqueles que a assistem.

Esta busca dos meios de comunicação por um lugar de importância na história é analisada por Barbosa (2016). Segundo ela, os meios de comunicação, de maneira geral, produzem uma articulação textual baseada na noção de testemunho. A partir do nível declaratório do testemunho, efetuam uma versão do acontecimento com a pretensão de ser, desde sua construção, uma espécie de arquivo para a história. Dessa forma e de acordo com o seu texto, se fizesse-se uma generalização, o que os meios de comunicação fazem é produzir relatos válidos e amplamente reconhecíveis, inserindo-os na história.

Portanto, o programa produziu uma narrativa repleta de desejos do passado e da construção de um legado para a posteridade. A narrativa é construída para permanecer e ser reutilizada. Portanto, a Rede Globo, nesta perspectiva, deseja ser arquivo da e para a história. Assim, o jogo memorável que os meios de comunicação realizam produzem narrativas para um lugar na história e não na memória. Para isso, de acordo com Barbosa (2016, p. 22), “[...] se valem de artimanhas memoráveis nas quais a formação de campos de esquecimento em camadas sobrepostas, às quais são acrescentadas sempre uma nova camada, se constituem como artifício da narrativa”.

\section{O lugar ocupado pela emissora}

A partir da base teórica mencionada, neste momento do trabalho, tem-se por objetivo a observação de como a emissora, por meio do programa "Especial Globo 50 anos”, buscou 
mediar os lugares que ocupa perante seus receptores. Em especial, buscamos compreender qual é o lugar histórico e qual é o sentido histórico que foi construído por sua narrativa.

A fim de atender a tais objetivos, utilizamos a metodologia proposta pela pesquisadora Iluska Coutinho, apresentada e publicada em 2016. Segundo ela, seu texto foi produzido com o propósito de tornar possível um método que analise o audiovisual, considerando as particularidades de seus produtos: desde a dimensão material e estética até os sentidos que deles emergem (produção e recepção). A este método, a autora denominou de "Análise da Materialidade Audiovisual”. Em suma, ele consiste em uma análise que não realiza operações de decomposição que, segundo ela, descaracterizariam a enunciação e a produção de sentidos do audiovisual. Para tal intento, delimitam-se quatro passos, explicitados a seguir, a fim de concretizar a análise.

Em um primeiro momento, busca-se identificar o objeto empírico a ser analisado, com vistas às questões da pesquisa e seus elementos paratextuais (peritexto - aquilo que vem antes -, e paritexto - aquilo que vem depois de sua enunciação). A autora trabalha, também, nesta fase inicial, com o “Contrato de Leitura” de Verón (2004) e com o modelo de “Promessa” de Jost (2007). Além disso, propõe-se que, antes de realizar a etapa de análise, é importante reconhecer os sentidos propostos por determinado programa ou produto audiovisual para o seu público ou para a própria mídia onde se inscreve.

Em um segundo momento, mostra-se necessário elaborar uma ficha de leitura e avaliação. A análise é de cunho qualiquantitativo, e os itens de avaliação que devem ser identificados são: temática, caracterização das fontes de informação, presença ou não de pontos de vista conflitais, presença de arte, entre outros.

Em um terceiro momento, busca-se delimitar a amostra a ser investigada, para depois obtê-la, digitalizá-la e armazená-la. De acordo com a autora, devem ser definidos, nesta fase da pesquisa, critérios tais como a representatividade, a exaustividade, a disponibilidade, a pertinência aos objetivos e parâmetros de pesquisa e, por fim, a periodicidade de produção ou veiculação.

Na fase propriamente dita de análise, caracterizada como o quarto momento, é fundamental a realização de registros que busquem, por meio da percepção e descrição dos resultados obtidos, tomar como objeto de estudo e narrativa as características daquele produto. Além disso, é importante, também, reconhecer as promessas e os laços assumidos por cada narrativa.

A análise do programa "Especial Globo 50 anos" embasou-se, portanto, nesta proposta metodológica, e seguirá os quatro procedimentos definidos pela autora. Nas próximas páginas, portanto, serão explicitados, por meio deste método, os resultados obtidos na observação do programa supracitado.

Dessa forma, este artigo se propõe responder a duas questões basilares: (i) que lugares a Rede Globo pretendeu ocupar por meio do programa? (ii) Que imagem a emissora busca sedimentar perante os receptores do programa? 
A fim de responder a essas perguntas, mostra-se primordial compreender que a análise de determinado programa televisivo não deve se basear estritamente em seu produto de emissão, mas, sim, levar em consideração o que se fala a seu respeito e em qual contexto foi produzido. Essa preocupação é uma das premissas apontadas por Jost (2007), em texto que defende o modelo de promessa ao se estudar produtos audiovisuais. Este modelo de análise é definido como um acordo no qual o emissor e receptor reconhecem que se comunicam e o fazem por razões compartilhadas.

Outro ponto importante apontado por Jost (2007) é a questão de que o gênero é uma interface, que permite a conexão entre emissor e telespectador. De acordo com ele, os gêneros contêm dois tipos de promessa: uma ontológica (transmissões ao vivo que trazem a promessa de autenticidade maior que em outros programas); e uma promessa pragmática (que consiste na atribuição feita antecipadamente pelas emissoras quando há a denominação de gênero a uma emissão). O conceito de gênero é, portanto, essencial para o modelo de promessa, pois este exerce funções na comunicação televisual. $\mathrm{O}$ autor aponta que o gênero permite à TV agir no interior de um quadro semântico do telespectador. Outro ponto a se destacar é o poder de informação contido na definição de um gênero. Há também a noção de arquivagem.

Por último, salienta-se que a determinação de gênero é relativa a aspectos de regularização das produções televisivas, que tem repercussões econômicas fortes. Nesse sentido, quando uma emissora determina em qual categoria ou classificação seus programas serão inseridos, esta determinação não acontece de forma imparcial; busca-se potencializar valores às emissões. Dessa forma, as promessas constituem-se em estratégias mercadológicas para as emissoras, e buscam, também, direcionar, através de suas delimitações, a interpretação por parte de seus receptores.

Por fim, Jost (2007) enfatiza que a relação comunicacional no modelo da promessa acontece em dois tempos. Em um primeiro momento, o telespectador aceita a promessa do programa televisivo, seja a de chorar no caso de um drama, seja a de se divertir num programa de auditório, ou ter acesso à realidade num telejornal. Em um segundo momento, o telespectador verificará se a promessa foi efetivada. De forma geral, este modelo exige uma participação ativa do telespectador.

Especificamente no que se refere ao programa analisado neste artigo, ao final dos créditos, lê-se a aderência dele ao setor de entretenimento da Rede Globo. Entretanto, ainda que o programa se configure como um show de rememoração, a narração se concretiza na fala de dois jornalistas renomados do casting da emissora (Fátima Bernardes e Pedro Bial). É importante definir o que esta escolha traz como consequências para a narrativa, uma vez que são jornalistas narrando um programa de entretenimento.

Esta constatação seria uma incoerência por parte da emissora ou os jornalistas ocupavam um lugar de fala fundamental para a narrativa construída?

Segundo Schuster (2016, p. 178), 
[...] os sujeitos, obrigatoriamente, situam-se em algum lugar (que, a priori, é social), quando da prática enunciativa. São detentores de papéis e identidades distintas, que serão impressas no discurso. Durante o estabelecimento de um ato comunicativo, instaura-se um quadro de referência sustentado por formações imaginárias que nos dão a dimensão dos lugares de cada participante.

De acordo com Pêcheux (2009), as narrações mudam de sentido conforme as posições sustentadas por aqueles que as empregam. Dessa forma, o lugar social, representado pelo lugar empírico, institucional, atravessado por relações de poder, arbitra o lugar de fala. Isso que dizer que o lugar é constitutivo da fala do sujeito. Por isso, o lugar de fala do jornalismo, segundo Schuster (2016), é o de poder dizer das coisas do mundo. Além disso, o lugar da imprensa brasileira é, de acordo com seus estudos, sedimentado como objeto neutro e imparcial. Por isso, a narração dos jornalistas no “Especial Globo 50 anos” assume papel primordial ao dar ao objeto narrado o grau de objetividade, neutralidade e imparcialidade próprios da atividade jornalística. Para um programa que pretende rememorar a trajetória institucional da emissora, a fala dos jornalistas atribui à narrativa, em última instância, uma promessa de credibilidade e de verdade.

Ainda se utilizando o modelo de promessa proposto por Jost (2004), é necessário atribuir significância ao fato de o programa estar inserido num momento de comemoração do cinquentenário da emissora. Qual é a importância deste contexto? O que se espera de um programa que surge neste contexto?

Segundo Barbosa (2006, p. 14), “[...] sem dúvida, as comemorações constituem uma das estratégias de multiplicação de práticas voltadas para o exercício de construção do passado que produz uma espécie de dilatação do campo memorável na contemporaneidade”. Assim, para ela, rememorar possibilita os usos do passado no presente como forma de balizar as memórias de acordo com lógicas do contexto de produção. Além disso, é importante não perder de vista que lembrar é esquecer: “[...] a memória só é possível a partir do esquecimento. Assim, comemorar, antes de recordar, é esquecer” (BARBOSA, 2006, p. 15).

Ricoeur (2007) considera o esquecimento como memória impedida, como memória manipulada e como esquecimento comandado. "Se há, portanto, uma vontade de memória politicamente desejável, também existe uma política de esquecimento público. Como lembra, Huyssen (2000), nenhuma memória política pode funcionar sem esquecimento” (BARBOSA, 2006, p. 16).

Respondendo as questões citadas anteriormente, o contexto de produção permite à emissora utilizar o passado como forma de instaurar uma nova posição social e também de sedimentar seu poder enquanto agente histórica, promovendo, assim, uma mediação de sua historicidade. "Mesmo os acontecimentos dignos de lembrança reiteram, como é o caso daqueles que precisam ser comemorados publicamente, instauram o esquecimento" (BARBOSA, 2006, p. 16). Dessa forma, ao comemorar-se o cinquentenário, lembra-se daquilo que a qualifica e esquecem-se de todos os deméritos ao longo de seus anos de existência. 
O programa possui um total de 1h, 14min e 31seg. A partir da metodologia da análise da materialidade audiovisual, foi feita a transcrição das informações (falas e elementos considerados importantes para as questões colocadas). Em um primeiro momento, é importante destacar o desejo de mediar o lugar que a Rede Globo ocupa na história. Em vários momentos, como salientaremos, a narrativa é feita da e para a História.

São múltiplos os modos de exaltação que procuram ressaltar sua importância e seu legado. Como exemplo, há a fala dos jornalistas que abordam a fundação da emissora como um fato histórico na vida dos brasileiros.

Pedro Bial: “Muito boa noite! Bem-vindos! Olha, há cinquenta anos nascia aqui no Rio de Janeiro, pertinho de onde nós estamos, a TV Globo, canal 4”. Fátima Bernardes: "Ao vivo e em preto e branco, entrava no ar, na manhã do dia 26 de abril de 1965, a mais nova emissora de TV do país. Carioca de nascença, brasileira de coração”. Pedro Bial: “Um sonho, ou melhor, a grande aposta de um homem de 60 anos apaixonado por informação e apaixonado pelo Brasil. O jornalista Roberto Marinho. Na idade em que nós já estamos pensando em aposentadoria, ele foi à luta e todos ganhamos com diversão e informação”. Fátima Bernardes: “Hoje, vamos festejar juntos estes 50 anos de emoção em série”. Pedro Bial: "Emoções que compartilhamos no jornalismo, nas novelas, no esporte, nos shows da vida”. Fátima Bernardes: “Na realidade e na ficção, que nos marcaram, nos uniram, nos transformaram, e que continuam a nos emocionar e a nos surpreender todos os dias, a cada nova estreia, a cada plantão de notícia”.

A necessidade de delimitar um lugar na história aparece em outros momentos, tais como nas falas de Galvão Bueno: “[...] eles fizeram a história do esporte brasileiro e agora dividem com vocês. Brasil!”. Aparece até mesmo na fala de Pedro Bial com relação às séries brasileiras: “[...] agora é hora de lembrar as séries que contaram e recontaram a história do Brasil para o Brasil”. E continua ele: “[...] as minisséries demonstraram, com seu sucesso, como o povo brasileiro gosta de saber da história do Brasil. Como é que foi o processo de construção desta nação. Aliás, processo que continua em andamento. A história política do Brasil em JK!”.

Em sua fala final, ele traz os termos História e Memória.

Segundo Bial: “tanta história, tanta memória. Acabei me lembrando de uma frase de um dos pioneiros da Globo. O genial Otto Lara Resende. Pensando no tempo que passa assim, ele disse: ultimamente passaram-se muitos anos.” Mais uma vez, constata-se a necessidade de delimitar a emissora não somente como agente de memória, mas de história.

Por fim, segundo Barbosa (2006), além de desejos de passado, as enunciações comemorativas trazem promessas de futuro. "Além de serem construtores privilegiados do passado, os meios de comunicação são lugares de representação do futuro. O futuro, com sua imprecisão e incerteza, passa a ser o centro de construções cotidianas que o fazem emergir já no presente, comprimindo o tempo do agora” (BARBOSA, 2006, p. 16). As comemorações seriam o modo de representação mais emblemático das expectativas de futuro, pois na presentificação do passado, os meios de comunicação apresentam também 
uma expectativa de futuro. Nesse sentido, de acordo com ela, o momento memorial aparece como intensificador do presente dilacerado pelas utopias, em que os recursos à tradição possuem apenas valor performativo.

Na emissão do cinquentenário, voltou-se para o futuro no ato rememorativo. É possível perceber este fato na utilização dos advérbios de tempo ao final da narração tanto na fala das jovens personalidades da emissora - Bruna Marquezine: "e o que vem depois dos 50? Depois de ter feito tanto”. Bruno Gissoni: “depois de ter encantado tanto, emocionado tanto”. Letícia Colin: “depois do beijo, depois dos carinhos, depois dos olhares, do tato, do contato. Depois de avenidas, selvas, reinos, impérios e vidas”. Nathália Dill: “do chute, da rede, da cortada, do ataque e da defesa. Depois do grito, do silêncio, da torcida, do que sai da garganta”. Marcello Melo Jr.: “depois do plantão, da informação, da dedicação, da sua colaboração”. Fernanda Gentil: “e depois dos risos, das lágrimas, do eu te amo, do eu te odeio”. Jayme Matarazzo: “o que vem depois da vida, o que vem depois de hoje?”. Marina Ruy Barbosa: “seja lá como for o futuro, nós vamos descobrir isso juntos” - quanto nas falas dos jornalistas narradores - Fátima Bernardes: “hoje, o agora, já é amanhã. E o ontem já foi hoje”. Pedro Bial: “hoje faz tempo”. Fátima Bernardes: “hoje é o último dia dos primeiros”. Pedro Bial: "hoje é o último dia dos primeiros cinquenta anos”. Fátima Bernardes: "hoje é o primeiro dia dos próximos”. Pedro Bial: “hoje é o primeiro dia dos próximos pioneiros, hoje é o dia pioneiro, hoje é um primeiro dia”. Fátima Bernardes: “hoje é o último dia dos primeiros, hoje é o primeiro dia de novo”. Como afirma Barbosa (2006, p. 25), “[...] voltase sempre para o futuro, olhando necessariamente o passado”. O tempo das emissões da televisão é aberto para um futuro infinito.

\section{Considerações finais}

A busca da preservação memorialística pelas empresas, como destacado neste artigo, tornou-se uma preocupação latente das várias instituições da contemporaneidade, especialmente a partir da década de 1990. A Rede Globo, por meio de seu projeto "Memória Globo”, está inserida neste panorama e, com frequência, utiliza seu acervo memorial a fim de produzir programas que possam narrar sua trajetória.

Seu cinquentenário pode ser apontado como exemplo importante desta utilização. Só nesta ocasião, foram produzidos e exibidos especiais no "Jornal Nacional”, no "Vídeo Show”, ou mesmo no programa analisado por este artigo. A preservação memorialística da emissora potencializa os lucros comerciais, mas, de forma inequívoca, potencializa os lucros simbólicos perante o público que a assiste. A partir da análise feita sobre o "Especial Globo 50 anos”, foi possível constatar a busca de uma exaltação, de uma sedimentação do lugar social que a emissora ocupa. Exaltar, neste caso, significou ressaltar sua atuação como agente da história.

Como denominou Thompson (2009), é historicidade mediada quando os tempos pretéritos são retratados na mídia. A Rede Globo buscou, em síntese, balizar a memória para definir seu lugar e resguardar seu papel enquanto aquela que faz a história. 
Portanto, no presente de produção, utilizou-se do passado enquanto trajetória, com o propósito de destacar seu grande legado para a posteridade. Isso fica evidente nas falas dos jornalistas que narraram o programa e nas falas das jovens personalidades da emissora. Dessa forma, o programa articulou as três categorias temporais (passado, presente e futuro) a fim de ampliar o legado e o futuro da emissora enquanto agente da história.

Como limitações deste estudo e ainda sugestão para outros estudos complementares, propõe-se a ampliação do leque desta análise às demais ações da organização Rede Globo, como citados acima: especiais inseridos em outros programas sobre o cinquentenário e os bastidores destes especiais exibidos na “Globo News”. Análises trianguladas podem sugerir direcionamentos mais específicos da organização em relação à sua estratégia de posicionamento. Sugere-se, ainda, que seja adotada a mesma metodologia a outras organizações televisivas, a fim de compreender através da história e memória institucional como se estruturam os espaços e o poder simbólico midiático.

\section{Referências}

BARBOSA, M. Meios de comunicação: lugar de memória ou na história? Contracampo, Niterói, v. 35, n. 1, p. 7-26, abr./jul. 2016. Disponível em: http://www.contracampo.uff.br/index.php/revista/article/view/802. Acesso em: 18 ago. 2017.

BARBOSA, M. Mídias e usos do passado: o esquecimento e o futuro. Revista Galáxia, São Paulo, n. 12, p. 13-26, dez. 2006.

COUTINHO, I. O telejornalismo narrado nas pesquisas e a busca por cientificidade: a análise da materialidade audiovisual como método possível. In: CONGRESSO BRASILEIRO DE CIÊNCIAS DA COMUNICAÇÃO, 39, 2016, São Paulo. Anais [...]. São Paulo: Intercom - Sociedade Brasileira de Estudos Interdisciplinares da Comunicação, 2016. Disponível em: http://portalintercom.org.br/anais/nacional2016/resumos/R11-3118-1. pdf. Acesso em: 20 ago. 2017.

HALBWACHS, M. A Memória coletiva. São Paulo: Centauro, 2006. 189 p.

HUYSSEN, A. Seduzidos pela memória. Rio de Janeiro: Aeroplano, 2000. 116 p.

JOST, F. Compreender a televisão. Porto Alegre: Sulina, 2007. 165 p.

LE GOFF, J. História e memória. Campinas: Editora UNICAMP, 1996. 476 p.

LIPOVETSKY, G.; CHARLES, S. Os Tempos hipermodernos. São Paulo: Barcarolla, 2004. 128 p.

MOTTER, M. L. Ficção e história: imprensa e construção da realidade. São Paulo: Arte \& Ciência, Cillipress, 2001. 175 p.

NORA, P. O retorno do fato. In: LE GOFF J.; NORAT P. (orgs.) História: novos problemas. Rio de Janeiro: Francisco Alves, 1995. p. 179-193.

NORA, P. Entre memória e história: a problemática dos lugares. Projeto História, São Paulo, n. 10, p. 7-28, dez. 1993.

PAZIN, M. A importância dos centros de memória para as instituições e para a sociedade. 2015. Disponível em: http://www.itaucultural.org.br/a-importancia-dos-centros-de-memoria-para-as-instituicoese-para-a-sociedade. Acesso em: 22 ago. 2017. 
PÊCHEUX, M. Semântica e discurso: uma crítica à afirmação do óbvio. Trad.: Eni Pulcinelli Orlandi et al. Campinas: Editora da Unicamp, 2009. 317 p.

RICOEUR, P. A memória, a história, o esquecimento. Tradução Alain François. Campinas: Editora da Unicamp, 2007. $536 \mathrm{p}$.

SCHUSTER, P. R. O lugar de fala do jornalismo: temas sindicais em Veja e Revista do Brasil. Conexão: Comunicação e Cultura, Caxias do Sul, v. 15, n. 30, p. 176-193, jul./dez. 2016. Disponível em: www.ucs.br/ etc/revistas/index.php/conexao/article/download/4372/2847. Acesso em: 20 ago. 2017.

THOMPSON, J. A mídia e a modernidade: uma teoria social da mídia. Petrópolis: Editora Vozes, 2009. 261 p. VERÓN, E. Fragmentos de um tecido. São Leopoldo: UNISINOS, 2004. 286 p.

VICENTE, M. M. História e Comunicação na nova ordem internacional. São Paulo: Cultura Acadêmica, 2009. $214 \mathrm{p}$.

\section{Juliana Vieira Borges}

Professora do Departamento de Administração da Universidade Federal dos Vales do Jequitinhonha e Mucuri (Teófilo Otoni - MG) e doutoranda em Administração pela Universidade Federal de Lavras - MG. É mestre em Administração (2008) pela Universidade Federal de Viçosa - MG, e graduada em Administração (2006) e Ciências Econômicas (2003) também pela Universidade Federal de Viçosa - MG. Tem interesse em pesquisas com focadas em marketing, mais especificamente cultura do consumo, marketing de serviços e marketing digital. E-mail: julivborges@gmail.com.

\section{Humberto Junio Alves Viana}

Professor efetivo de História do Colégio Tiradentes da Polícia Militar (Lavras - MG), mestre em Comunicação pela Universidade Federal de Juiz de Fora - MG e graduado em História pela Universidade Federal de São João Del Rei - MG. Participa de grupos de pesquisa 'Comunicação Cidade, Memória’ (UFJF) e ‘Memória, Oralidade e Imagem’ (UFSJ). Tem interesse por pesquisas que analisem as relações entre história e mídia, memória e rememorações, telejornalismo, e influências socioculturais. E-mail: beto92beto@gmail.com.

\section{Christina Ferraz Musse}

Professora do curso de Jornalismo da Faculdade de Comunicação da Universidade Federal de Juiz de Fora - MG e professora visitante da Universidade de Paris VIII, Saint-Denis, na França. Mestre (2001) e doutora em Comunicação e Cultura pela Universidade Federal do Rio de Janeiro (2006), e pós-doutora pela Pontifícia Universidade Católica do Rio Grande do Sul (2017). É presidente da Rede Alcar - Associação Brasileira de Pesquisadores de História da Mídia, membro do Conselho Editorial da revista "A3" e integra o Conselho Editorial da "Revista Brasileira de História da Mídia”. Autora dos livros: “Imprensa, cultura e imaginário urbano: exercício de memória sobre os anos 60/70 em Juiz de Fora” (2007); "Memórias possíveis: personagens da televisão em Juiz 
de Fora” (com a colaboração de Cristiano José Rodrigues) (2011) e “Os cinemas de rua de Juiz de Fora: memórias do Cine São Luiz” (com a colaboração de Gilberto Faúla Avelar Neto e Rosali Maria Nunes Henriques). É coautora do livro "Memórias do cineclubismo: a trajetória do CEC - Centro de Estudos Cinematográficos de Juiz de Fora” (de autoria de Haydêe SantAna Arantes) (2014). É organizadora do livro “Comunicação e Universidade: reflexões críticas” (2019). Tem experiência na área de Comunicação, com ênfase em Videodifusão, atuando principalmente nos seguintes temas: comunicação, globalização, cultura, memória, cidade, identidade e televisão. E-mail: cferrazmusse@ gmail.com.

\section{Daniel Carvalho de Rezende}

Professor associado do curso de Administração da Universidade Federal de Lavras e Coordenador do Programa de Pós-Graduação em Administração (PPGA/UFLA) e um dos líderes do tema “Construção de Mercados” no Enanpad. Possui pós-doutorado em Marketing pela Lancaster University (2012), doutorado em Desenvolvimento, Agricultura e Sociedade pela Universidade Federal Rural do Rio de Janeiro (2004), mestrado em Administração pela Universidade Federal de Lavras (2000) e graduação em Engenharia da Produção pela Pontífica Universidade Católica do Rio de Janeiro (1997). Atua na área de Marketing, com destaque para os temas: consumo cultural e identidade, construção de mercados, consumo e marketing de alimentos. E-mail: rezendedc@gmail.com.

Recebido em: 06.05.2019

Aprovado em: 14.09.2020

Este artigo é publicado em acesso aberto (Open Access) sob a licença Creative Commons Attribution Non-Commercial (CC-BY-NC), que permite uso, distribuição e reprodução em qualquer meio, sem restrições, desde que sem fins comerciais e que o trabalho original seja corretamente citado. 